\title{
VARIAÇÕES DO CONTEÚDO DE CARBOIDRATOS EM GEMAS E RAMOS DE DOIS ANOS DE MACIEIRA EM REGIÃO DE BAIXA OCORRÊNCIA DE FRIO'
}

\author{
RUY INACIO NEIVA DE CARVALHO² \& FLÁVIO ZANETTE 3
}

\begin{abstract}
RESUMO - Objetivou-se analisar as variações do conteúdo de carboidratos em gemas e ramos de dois anos de idade de macieira 'Imperial Gala' com ou sem frio suplementar durante o outono e inverno, cultivadas em região de baixa ocorrência de frio. Os ramos foram coletados em Porto AmazonasPR, em intervalos de 21 dias, de abril a agosto (19-04, 10-05, 31-05, 21-06, 12-07, $02-08$ e 23-08) e receberam ou não tratamento com frio suplementar de 1.440 horas à temperatura de 4 a $7^{\circ} \mathrm{C}$. As análises de carboidratos foram realizadas em gemas e porções de ramos adjacentes às mesmas. Os carboidratos solúveis (CS) totais foram determinados pelo método do fenol-ácido sulfúrico, realizando-se a leitura por espectrofotometria (absorbância a $490 \mathrm{~nm}$ ). Os carboidratos insolúveis (CI) totais foram estimados pelo rendimento da fração de tecido vegetal insolúvel em álcool e solúvel em álcali, após liofilização. Existem significativas variações do conteúdo de carboidratos em gemas e ramos de dois anos durante a dormência. O aumento da intensidade de dormência no outono está associado à redução do conteúdo de CS em gemas. O tratamento com 1.440 horas de frio suplementar modifica significativamente as variações do conteúdo de CS em ramos e de CI em gemas.
\end{abstract}

Termos para Indexação: Malus domestica Borkh., 'Imperial Gala', fisiologia, dormência.

\section{VARIATIONS OF CARBOHYDRATE CONTENT IN TWO YEAR OLD BUDS AND STEMS OF APPLE TREES IN A REGION OF LOW CHILL OCCURENCE}

ABSTRACT - This work aimed to quantify the variation of carbohydrate content in two year old buds and stems of apple trees cv. 'Imperial Gala' with or without supplementary chill during autumn and winter, cultivated in a region of low chill occurence. The stems were collected in Porto Amazonas, Parana State, Brazil, at intervals of 21 days from April to August (April $19^{\text {th }}$, May $10^{\text {th }}$, May $31^{\text {st }}$, June $21^{\text {st }}$, July $12^{\text {th }}$, August $2^{\text {nd }}$ and August $\left.23^{\text {rd }}\right)$ and were either treated or not with 1,440 hours of chill $\left(4\right.$ to $\left.7^{\circ} \mathrm{C}\right)$. The carbohydrates were analysed in buds and stem tissues adjacent to the buds. The soluble carbohydrates (SC) were evaluated by the phenol-sulfuric acid method and the final determination was achieved by spectrophotometry (490 nm absorbency). The non-soluble carbohydrates (NC) were estimated by the mass of vegetal tissues insoluble in alcohol and soluble in alcaline medium, after freeze drying. Significant variations of carbohydrate content were observed in the two year old buds and stems during the dormancy. The increase of dormancy intensity in autumn is associated with the reduction of SC content in buds. The treatment with 1,440 hours of chill modify the variations of SC content in stems and NC content in buds.

Index terms: Malus domestica Borkh., 'Imperial Gala', physiology, dormancy.

\section{INTRODUÇÃO}

Durante as estações desfavoráveis, as plantas limitam ou cessam seu crescimento de forma a permitir a sobrevivência em períodos de escassez de água ou de baixas temperaturas, caracterizando o período de dormência. Nessa fase, as atividades metabólicas essenciais continuam a ocorrer, embora com intensidade reduzida (Petri et al., 1996).

A baixa temperatura é um fator ambiental de grande influência na dormência de gemas (Crabbé \& Barnola, 1996), em especial, de macieira (Pereira et al., 2001). Os processos fisiológicos internos envolvidos na entrada e saída da endodormência, período em que a brotação não ocorre por fatores externos à planta (Lang et al., 1987), podem estar relacionados com diversos fatores, dentre os quais o fluxo de carboidratos e a translocação de reservas a curta distância (Marquat et al., 1999).

Em rosáceas, a maior parte do carbono fixado na fotossíntese é armazenado na forma de amido no cloroplasto ou é transferido ao citossol e convertido nos carboidratos solúveis, sacarose e sorbitol (Quick \& Schaffer, 1996). Apenas traços de outros carboidratos são encontrados, como a rafinose, a estaquiose e o mioinositol (Salisbury $\&$ Ross, 1992). Desde a década de 1960, o sorbitol tem sido determinado como o principal assimilado translocado na macieira (Williams et al., 1967) e mais recentemente em outras rosáceas, como a pereira (Herter et al., 2001) e o pessegueiro (Marquat et al., 1999). A análise das variações do conteúdo de carboidratos em tecidos mais velhos durante a dormência pode auxiliar o entendimento da fisiologia da planta nessa importante fase de preparação para um novo ciclo de crescimento. Gemas mais velhas, uma vez estimuladas, podem brotar e formar novos ramos, favorecendo tanto a renovação quanto o equilíbrio de ramos estruturais e produtivos da planta.

Objetivou-se analisar as variações do conteúdo de carboidratos em gemas e ramos de dois anos de idade de macieira 'Imperial Gala' com ou sem frio suplementar durante o outono e o inverno, cultivadas em região de baixa ocorrência de frio.

\section{MATERIAL E MÉTODOS}

O trabalho foi realizado com ramos de dois anos de idade portadores de gemas dormentes de macieira 'Imperial Gala' coletados em pomar com cinco anos de idade conduzido em plantio adensado (4,0 x 1,35 m), na Fazenda Agropecuária Boutin, em Porto Amazonas - PR (25,55 latitude sul, $49,90^{\circ}$ de longitude oeste e $795 \mathrm{~m}$ de altitude). $\mathrm{O}$ frio ocorrido na região foi quantificado segundo o método do número de horas de frio abaixo de $7,2^{\circ} \mathrm{C}$ e pelo método da conversão de temperaturas para unidades de frio, conforme utilizou Carvalho (2001).

Os ramos com disposição espacial oblíqua foram coletados em sete períodos no ano de 2000 (19-04, 10-05, 31-05, 21-06, 12-07, $02-08$ e 23-08) e, em seguida, receberam ou não tratamento com frio suplementar de 1.440 horas, à temperatura de $4 \mathrm{a} 7^{\circ} \mathrm{C}$, em geladeira.

As análises de carboidratos foram realizadas separadamente em gemas e porções de ramos adjacentes às mesmas. As gemas foram destacadas por meio de corte com bisturi rente ao ramo, e as cinco escamas mais externas foram retiradas. Os ramos foram fracionados em porções com $1 \mathrm{~cm}$ de comprimento e divididos ao meio por um corte longitudinal, mantendo-se para análise a metade que possuía uma gema já eliminada. As determinações foram realizadas no Laboratório de Carboidratos de Exsudatos Vegetais do Departamento de Bioquímica e

${ }^{1}$ (Trabalho 087/2004). Recebido: 14/07/2007. Aceito para publicação: 06/10/2005. Parte da tese do primeiro autor apresentada à Universidade Federal do Paraná para obtenção do título de Doutor em Ciências.

${ }^{2}$ Eng. Agrônomo, Dr., Professor Titular do Centro de Ciências Agrárias e Ambientais da Pontifícia Universidade Católica do Paraná. Rodovia BR 376, Km 14, CEP 83010-500 - São José dos Pinhais - Paraná. Fone: (41) 299-4300. ruy.carvalho@pucpr.br.

${ }^{3}$ Eng. Agrônomo, Dr., Professor de Fruticultura do Departamento de Fitotecnia e Fitossanitarismo da Universidade Federal do Paraná. Rua dos Funcionários, 1540 , CEP 80035-050. Curitiba - Paraná. Fone: (41) 350-5650. flazan@ufpr.br. 
no Laboratório de Cromatografia e Espectrofotometria do Departamento de Química da Universidade Federal do Paraná

Os carboidratos solúveis totais foram determinados pelo método do fenol-ácido sulfúrico (Dubois et al., 1956). A extração etanólica foi realizada, tratando-se $100 \mathrm{mg}$ de amostra com $30 \mathrm{~mL}$ de etanol $80 \%$ por 30 minutos, a $100^{\circ} \mathrm{C}$, em banho-maria. Foram utilizadas alíquotas de $50 \mu \mathrm{L}$ das frações solúveis em etanol nas quais foram adicionados $450 \mu \mathrm{L}$ de água destilada e, posteriormente, $0,5 \mathrm{~mL}$ de fenol e $2,5 \mathrm{~mL}$ de ácido sulfúrico concentrado. A leitura foi realizada em espectrofotômetro por absorbância a $490 \mathrm{~nm}$. Calculou-se o conteúdo de carboidratos solúveis totais em $\mathrm{mg} . \mathrm{g}^{-1}$ de matéria seca de material vegetal.

Para a determinação dos carboidratos insolúveis totais, uma amostra de $20 \mathrm{mg}$ da fração insolúvel em etanol liofilizada foi tratada com hidróxido de sódio $0,02 \mathrm{~N}$ em tubo de ensaio, por 30 minutos, a $90^{\circ}$ C, para extração de carboidratos insolúveis (Marquat et al., 1999). A fração solúvel em álcali foi liofilizada, pesada, e o rendimento em compostos insolúveis em álcool foi calculado em $\mathrm{mg} \mathrm{g}^{-1}$ de matéria seca de material vegetal.

A análise estatística para as gemas e porções de ramos foi realizada separadamente, resultando em dois experimentos. O delineamento experimental adotado nos dois casos foi o de blocos casualizados, com três repetições, cujos tratamentos foram arranjados em parcelas subdivididas, em que as parcelas foram constituídas pelo tratamento ou não com frio suplementar, e as subparcelas, pelos sete períodos de coleta. A comparação entre médias de tratamentos foi feita pelo teste de Tukey, ao nível de significância de $5 \%$.

\section{RESULTADOS E DISCUSSÃO}

A quantidade de frio ocorrida na região até agosto foi de 386 horas de frio abaixo de $7,2^{\circ} \mathrm{C}$ ou 211,5 unidades de frio; porém, até julho, apenas 95 horas ou - 86,0 unidades de frio haviam sido acumuladas. Embora ainda não tenha sido definido o requerimento em frio para a macieira da cultivar estudada, segundo Petri et al. (1996), a macieira da cultivar 'Gala', que originou a cultivar 'Imperial Gala', requer 600 horas de frio abaixo de $7,2^{\circ} \mathrm{C}$ para a quebra da dormência, quantidade de frio muito além da ocorrida no pomar de macieiras estudado. Putti et al. (2003) também relataram que a macieira 'Gala' tem alta exigência em frio, e o tempo médio para brotação de suas gemas é reduzido pelo aumento do número de unidades de frio.

Os carboidratos totais, solúveis mais insolúveis, variaram de 13,6 a 24,0 \% na matéria seca de gemas e de 9,7 a 14,6 \% na matéria seca de ramos de dois anos de idade sem frio suplementar (Tabela 1), sendo constituintes essenciais destes tecidos. Resultados similares foram constatados com gemas e ramos de macieira 'Imperial Gala' de um ano de idade, cujos valores variaram de 13,8 a $20,2 \%$ e de 9,9 a $15,3 \%$ respectivamente (Carvalho, 2001). As variações sazonais do conteúdo de carboidratos totais não devem ser analisadas isoladamente, pois significativas oscilações dos conteúdos de carboidratos solúveis (CS) e insolúveis (CI) podem sugerir a utilização do carbono para a respiração, transporte ou armazenamento nos tecidos (Preiss \& Sivak, 1996; Quick \& Schaffer, 1996).

TABELA 1 - Conteúdo (\%) de carboidratos totais em gemas e ramos de dois anos de macieira da cultivar 'Imperial Gala' que receberam ou não 1.440 horas de frio suplementar no período de abril a agosto de 2000 .

\begin{tabular}{ccccc}
\hline & \multicolumn{2}{c}{ Sem frio suplementar } & \multicolumn{2}{c}{ Com frio suplementar } \\
\cline { 2 - 5 } Datas & Gemas & Ramos & Gemas & Ramos \\
\hline $19-04$ & 18,1 & 10,5 & 20,4 & 13,6 \\
$10-05$ & 13,6 & 14,0 & 19,5 & 12,9 \\
$31-05$ & 13,9 & 11,6 & 18,9 & 13,9 \\
$21-06$ & 17,9 & 9,7 & 19,2 & 12,1 \\
$12-07$ & 24,0 & 13,7 & 18,3 & 9,3 \\
$02-08$ & 20,4 & 14,3 & 18,0 & 12,4 \\
$23-08$ & 19,0 & 14,6 & 16,5 & 10,8 \\
\hline
\end{tabular}

Houve interação significativa entre o tratamento com frio e as datas de coleta para o conteúdo de CS totais nas gemas $\left(\mathrm{F}_{\text {frio }}=1623,5\right.$; $\left.\mathrm{F}_{\text {época }}=55 ; \mathrm{F}_{\text {frioxépoca }}=11\right)$ e nos $\operatorname{ramos}\left(\mathrm{F}_{\text {frio }}=226,4 ; \mathrm{F}_{\text {época }}=36,3 ; \mathrm{F}_{\text {frioxépoca }}=\right.$ $102,2)$. Os CS totais em gemas que não receberam frio suplementar foram reduzidos de abril a junho, e nos meses seguintes houve pequena variação (Figura 1). Nas plantas estudadas, a intensidade de dormência de gemas de dois anos aumentou até o mês de maio e manteve-se elevada até julho (Carvalho, 2001). Desta forma, o aumento da intensidade de dormência no outono está associada à redução do conteúdo de CS nas gemas. Esta redução na entrada da dormência das gemas ocorreu provavelmente em virtude de seu transporte a curtas distâncias e utilização para a manutenção do metabolismo vital da planta por meio da respiração dos tecidos. O aumento de CS até julho, nas porções de ramos adjacentes às gemas (Figura 2), enfatiza a provável exportação dos mesmos pelas gemas, uma vez que o acúmulo de CS (glucose, frutose, sacarose, sorbitol e outros) em ramos ocorre, em especial, por transporte de outro órgão em virtude da inaptidão dos tecidos à fotossíntese. Da mesma forma, nestes meses de abril e maio, as folhas velhas e senescentes, ainda persistentes na planta, além de já não serem mais fontes de fotoassimilados em decorrência da degradação de clorofila e perda da capacidade funcional de cloroplastos (Salisbury \& Ross, 1992), também se caracterizam como drenos definitivos de carbono em virtude de sua abscisão. Gemas de dois anos não possuem folhas próximas a elas e, nessa fase de paralisação de crescimento da planta, o transporte só seria possível a distâncias curtas, pois, mesmo em períodos de crescimento, os fotoassimilados são distribuídos a tecidos adjacentes às suas fontes (Thorpe \& Minchin, 1996).

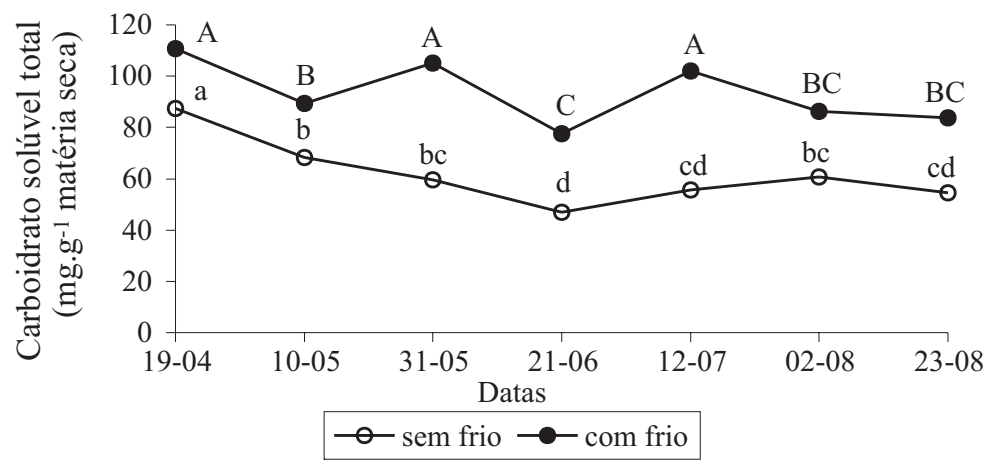

FIGURA 1 - Carboidratos solúveis totais em gemas de dois anos de macieira da cultivar 'Imperial Gala' que receberam ou não 1.440 horas de frio suplementar de 4 a $7^{\circ} \mathrm{C}$. Médias seguidas por letras distintas diferem entre si, pelo teste de Tukey, ao nível de significância de $5 \%$ (DMS = 10).

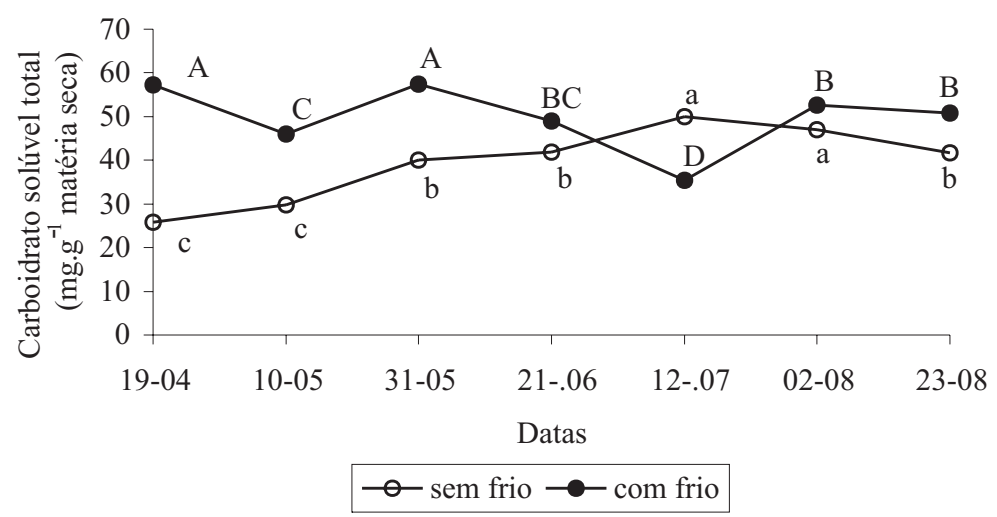

FIGURA2 - Carboidratos solúveis totais em porções de ramos adjacentes às gemas de dois anos de macieira da cultivar 'Imperial Gala' que receberam ou não 1.440 horas de frio suplementar de 4 a $7^{\circ} \mathrm{C}$. Médias seguidas por letras distintas diferem entre si, pelo teste de Tukey, ao nível de significância de $5 \%$ (DMS = 4,5). 
A mobilização de CS, em especial a glucose, para síntese de CI, em especial o amido, possivelmente não ocorreu nessa fase de entrada em dormência. A síntese de amido pela via mais conhecida da adenosina difosfato glucose (ADPglucose) é catalisada pela enzima adenosina difosfato glucose pirofosforilase (ADPGlcPPase), cujo maior ativador em tecidos não fotossintetizantes é o ácido 3-fosfoglicérico (3-PGA) (Preiss \& Sivak, 1996), produto da fotossíntese cujo transporte a partir de fontes de fotoassimilados (folhas) é restrito a períodos de atividade fotossintética (Quick \& Schaffer, 1996). De fato, as variações do conteúdo de $\mathrm{CI}$ (carboidratos de reserva e imóveis na planta) em gemas $\left(\mathrm{F}_{\text {frio }}=16,5 ; \mathrm{F}_{\text {época }}=9,2 ; \mathrm{F}_{\text {frioxépoca }}=12,7\right)$ e $\operatorname{ramos}\left(\mathrm{F}_{\text {frio }}=1,4 ; \mathrm{F}_{\text {época }}=1,5 ;\right.$ $\left.\mathrm{F}_{\text {frioxépoca }}=1,3\right)$ de dois anos que não receberam frio suplementar, não foram significativas nos meses de abril e maio (Figuras 3 e 4 ).

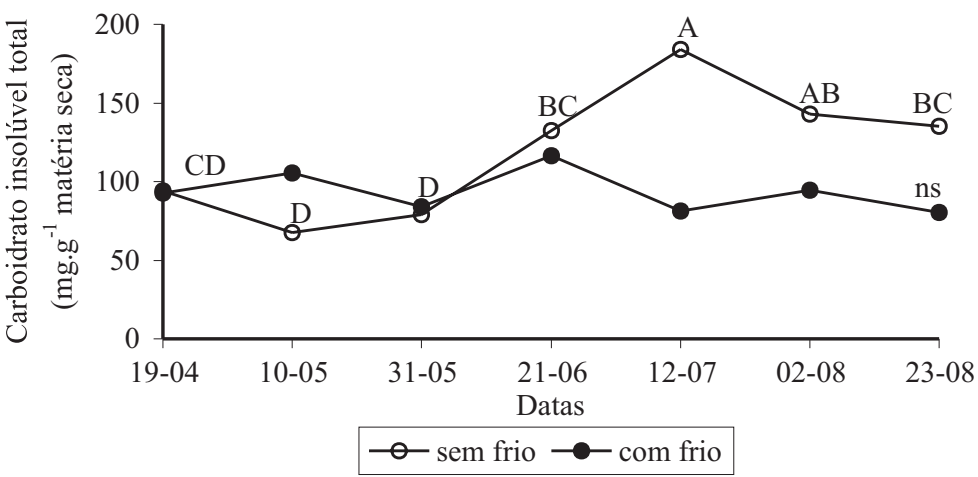

FIGURA 3 - Carboidratos insolúveis totais em gemas de dois anos de macieira da cultivar 'Imperial Gala' que receberam ou não 1.440 horas de frio suplementar de 4 a $7^{\circ} \mathrm{C}$. Médias seguidas por letras distintas diferem entre si, pelo teste de Tukey, ao nível de significância de $5 \%(D M S=41,8)$. (ns - diferenças não significativas).

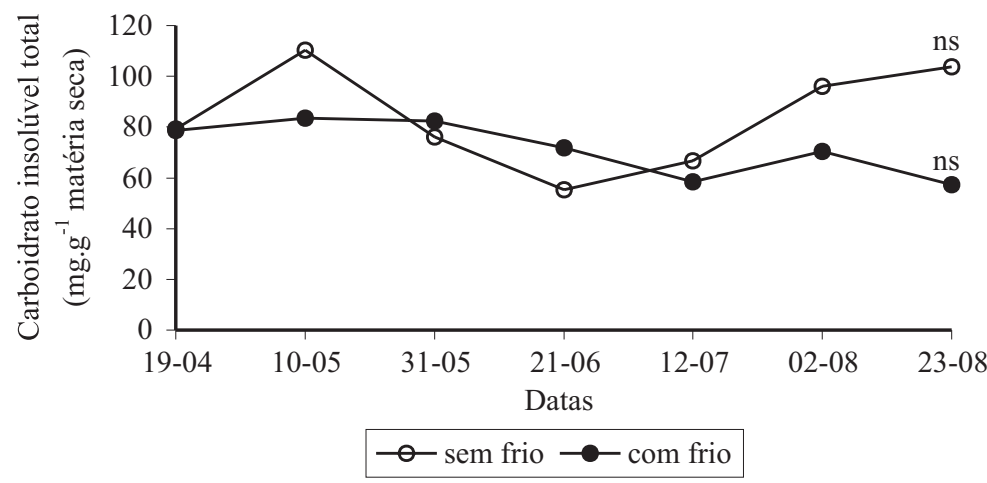

FIGURA 4 - Carboidratos insolúveis totais em porções de ramos adjacentes às gemas de dois anos de macieira da cultivar 'Imperial Gala' que receberam ou não 1.440 horas de frio suplementar de 4 a $7^{\circ} \mathrm{C}$. (ns - diferenças não significativas, pelo teste de Tukey, ao nível de significância de $5 \%$, DMS $=61,2)$.

As gemas tratadas com frio suplementar apresentaram conteúdo de CS superior às não tratadas, embora esta diferença não tenha evitado a redução desse conteúdo de abril até junho (Figura 1). Porém, nos ramos tratados com frio, também ocorreu perda de CS, até seu conteúdo tornar-se menor que nos ramos não tratados em julho, ao contrário do que ocorreu quando a redução do frio no ambiente foi gradual e menos intensa (Figura 2). Neste caso, o transporte de CS para regiões dos ramos distintas das analisadas, mais distantes das gemas, assume maior importância uma vez que não ocorreram variações significativas no conteúdo de CI (Figuras 3 e 4) e a intensidade respiratória seja reduzida pelo tratamento com frio. Desta forma, a intensidade de frio e a taxa de resfriamento podem induzir uma mudança no direcionamento do fluxo de carboidratos. Em geral, a primeira resposta da planta à baixa temperatura é a inibição do transporte, mas a retomada do fluxo pode ocorrer mesmo sob a continuidade de baixas temperaturas (Thorpe \& Minchin, 1996).

Após o pico de dormência ocorrida em maio, no pomar (Carvalho, 2001), ocorreu acúmulo de CI nas gemas que não receberam frio suplementar (Figura 3) sem, no entanto, ter havido redução de CS tanto nas gemas quanto nos ramos (Figuras 1 e 2), indicando que, com a evolução do frio, embora pouco intenso, há um redirecionamento natural do fluxo de CS em direção à gema. Parte deles estaria mobilizada para síntese de carboidratos de reserva, talvez por uma via diferente da ADPglucose, mas representando uma etapa de preparo para futura brotação. Uma vez que o amido possui efeito osmótico desprezível (Preiss \& Sivak, 1996), o nível de CS com funções de regulação osmótica e resistência dos tecidos ao congelamento (Loescher \& Everard, 1996) deve também ser mantido nos tecidos para passagem do inverno. No período de dormência, esta manutenção do conteúdo de CS pode ocorrer pela redistribuição de outras regiões dos ramos diferentes das estudadas. O tratamento com frio suplementar modificou esta dinâmica, mantendo os níveis de CI constantes ao longo de todo o período em gemas e ramos (Figura 3), desta forma bloqueando a síntese de CI e alterando um modelo de distribuição de CS.

\section{CONCLUSÕES}

1. Há significativas variações do conteúdo de carboidratos em gemas e ramos de dois anos de macieira 'Imperial Gala' durante o outono e inverno em região de baixa ocorrência de frio.

2. O aumento da intensidade de dormência no outono está associado à redução do conteúdo de carboidratos solúveis em gemas de macieira 'Imperial Gala'.

3. O tratamento com 1.440 horas de frio suplementar alterou significativamente as variações do conteúdo de carboidratos solúveis em ramos e de carboidratos insolúveis em gemas de macieira 'Imperial Gala'.

\section{REFERÊNCIAS}

CARVALHO, R. I. N. Dinâmica da dormência e do conteúdo de carboidratos e proteínas em gemas vegetativas e ramos de um e dois anos de macieira com ou sem frio suplementar. 2001. 134f. Tese (Doutorado em Produção Vegetal), Setor de Ciências Agrárias, Universidade Federal do Paraná, Curitiba, 2001.

CRABBÉ, J.; BARNOLA, P. A. New conceptual approach to bud dormancy in woody plants. In: LANG, G. A. (Ed.) Plant dormancy: physiology, biochemistry and molecular biology. New York: CAB International, 1996. p.83-113.

DUBOIS, M.; GILLES, K. A.; HAMILTON, J. K.; REBERS, P. A.; SMITH, F. Colorimetric method for determination of sugars and related substances. Analytical chemistry, Washington, v.28, n.3, p.350$356,1956$.

HERTER, F. G.; GARDIN, J. P. P.; BACARIN, M.; TREVISAN, R.; VERÍSSIMO, V. Níveis de carboidratos em tecidos de pereira cv. Nijisseiki em duas épocas que antecedem o florescimento. In: CONGRESSO BRASILEIRO DE FISIOLOGIA VEGETAL, 8., 2001, Ilhéus. Anais... Ilhéus: CEPLAC, 2001. CD-ROM.

LANG, G. A.; EARLY, J. D.; MARTIN, G. C.; DARNELL, R. L. Endo-, para- and ecodormancy: physiological terminology and classification for dormancy research. Hortscience, Alexandria, v.22, p.371-378, 1987 .

LOESCHER, W. H.; EVERARD, J. D. Sugar alcohol metabolism in sinks and sources. In: ZAMSKI, E.; SCHAFFER, A. A. Photoassimilate distribution in plants and crops: source-sink relationships. New York: Marcel Dekker, 1996. p.185-207.

MARQUAT, C.; VANDAMME, M.; GENDRAUD, M.; PÉTEL,G. Dormancy in vegetative buds of peach: relation between carbohydrate absorption potentials and carbohydrate concentration in the bud during dormancy and its release. Scientia 
Horticulturae, Amsterdam, v.79, p.151-162, 1999.

PEREIRA, J. E. S.; FORTES, G. R. L.; SILVA, J. B. Efeito da aplicação de baixa temperatura em plantas de macieira sobre o crescimento durante a aclimatização. Pesquisa Agropecuária Brasileira, Brasília, v.36, n.1, p.89-95, 2001.

PETRI, J. L.; PALLADINI, L. A.; SCHUCK, E.; DUCROQUET, J. P.; MATOS, C. S.; POLA, A. C. Dormência e indução da brotação de fruteiras de clima temperado. Florianópolis: EPAGRI, 1996. 110p. (Boletim Técnico, 75).

PREISS, J.; SIVAK, M. N. Starch synthesis in sink and sources. In: ZAMSKI, E.; SCHAFFER, A. A. Photoassimilate distribution in plants and crops: source-sink relationships. New York: Marcel Dekker, 1996. p.63-96.

PUTTI, G. L.; PETRI, J. L.; MENDEZ, M. E. Temperaturas efetivas para a dormência da macieira (Malus domestica Borkh.). Revista Brasileira de Fruticultura, Jaboticabal, v.25, n.2, p.210-212, 2003.
QUICK, W. P.; SCHAFFER, A. A. Sucrose metabolism in sources and sinks. In: ZAMSKI, E.; SCHAFFER, A. A. Photoassimilate distribution in plants and crops: source-sink relationships. New York: Marcel Dekker, 1996. p.115-156.

SALISBURY, F. B.; ROSS C. W. Plant physiology. Califórnia: Wadsworth Publishing Company, 1992. 682p.

THORPE, M. R.; MINCHIN, P. E. H. Mechanisms of long- and shortdistance transport from sources to sinks. In: ZAMSKI, E.; SCHAFFER, A. A. Photoassimilate distribution in plants and crops: source-sink relationships. New York: Marcel Dekker, 1996. p.261282.

WILLIAMS, M. W.; MARTIN, G. C.; STAHLY, E. A. The movement and fate of sorbitol- ${ }^{14} \mathrm{C}$ in the apple tree and fruit. Proceedings of the American Society for Horticultural Science, Geneva, v.90, p.2024, 1967. 